\title{
BEWARE OF MASQUERADERS- ATYPICAL PRESENTATION OF BRONCHOGENIC CARCINOMA
}

Siva Ashish Mallam¹, Subramanian Suriyan², Rajalakshmi Rajagopalan³, Nalini Jayanthi Nagesh", Saranya Kandaswamy5

1 Postgraduate Resident, Department of Respiratory Medicine, SRM Medical College Hospital and Research Centre, Chengalpattu, Tamilnadu.

2Professor, Department of Respiratory Medicine, SRM Medical College Hospital and Research Centre, Chengalpattu, Tamilnadu. ${ }_{3}^{3}$ Assistant Professor, Department of Respiratory Medicine, SRM Medical College Hospital and Research Centre, Chengalpattu, Tamilnadu.

${ }^{4}$ Professor and HOD, Department of Respiratory Medicine, SRM Medical College Hospital and Research Centre, Chengalpattu, Tamilnadu.

${ }^{5}$ Assistant Professor, Department of Pathology, SRM Medical College Hospital and Research Centre, Chengalpattu, Tamilnadu.

HOW TO CITE THIS ARTICLE: Mallam SA, Suriyan S, Rajagopalan R, et al. Beware of masqueraders- atypical presentation of bronchogenic carcinoma. J. Evolution Med. Dent. Sci. 2018;7(15):1936-1939, DOI: 10.14260/jemds/2018/436

\section{PRESENTATION OF CASE}

A 56-year-old male presented with complaints of cough with expectoration for 3 months duration and fever for 15 days. He had no associated complaints of breathlessness, wheeze, loss of weight and appetite. For the above complaints, he had received two courses of antibiotics before this presentation elsewhere. He is a smoker for 30 years. There is no significant past medical history. There was no evidence of similar illness in the family. On presentation, patient had investigations done outside like chest $\mathrm{x}$-ray that revealed a right upper and mid-zone cavity and CT thorax that revealed a cavity with fluid level with no evidence of lymphadenopathy or bone erosion. On examination, he was tachypnoeic with respiratory rate of $32 / \mathrm{min}$, pulse rate was $90 / \mathrm{min}$ and saturation was $95 \%$ on room air. He had no clubbing or lymphadenopathy. Respiratory examination revealed expiratory rhonchi and diminished breath sounds in right mammary, infra-axillary and infrascapular areas.

\section{DIFFERENTIAL DIAGNOSIS}

The possible Differential Diagnosis with above presentation include infective conditions like Tuberculosis, Necrotising Pneumonia/ Lung Abscess, Pneumatocoele, Coccidioidomycosis, Actinomycosis, Nocardiosis and Melioidosis. Other differentials include cavitating malignancies of the lung like squamous cell carcinoma and adenocarcinoma (rarely). Wegener's granulomatosis, rheumatoid nodules and congenital lung lesions like congenital cystic adenomatoid malformation (CCAM), pulmonary sequestration and bronchogenic cyst.

\section{CLINICAL DIAGNOSIS}

Blood investigations were in acceptable limits. Chest x-ray (Fig. 1) revealed right mid-zone cavity with air fluid level. On evaluation in this hospital, patient had no response clinically and radiologically to the antibiotics taken outside before this presentation. The diagnosis of non-resolving/ slowly resolving Pneumonia was considered based on the clinical picture.

'Financial or Other Competing Interest': None.

Submission 26-02-2018, Peer Review 23-03-2018,

Acceptance 29-03-2018, Published 09-04-2018.

Corresponding Author:

Dr. Subramanian Suriyan

Professor, Department of Respiratory Medicine,

SRM Medical College Hospital and Research Centre

Chengalpattu-603211 Tamilnadu.

E-mail:drssmani@gmail.com

DOI: $10.14260 / \mathrm{jemds} / 2018 / 436$

\section{(c) (i) $(9$}

Further evaluation was done to investigate the cause for non-resolving pneumonia.

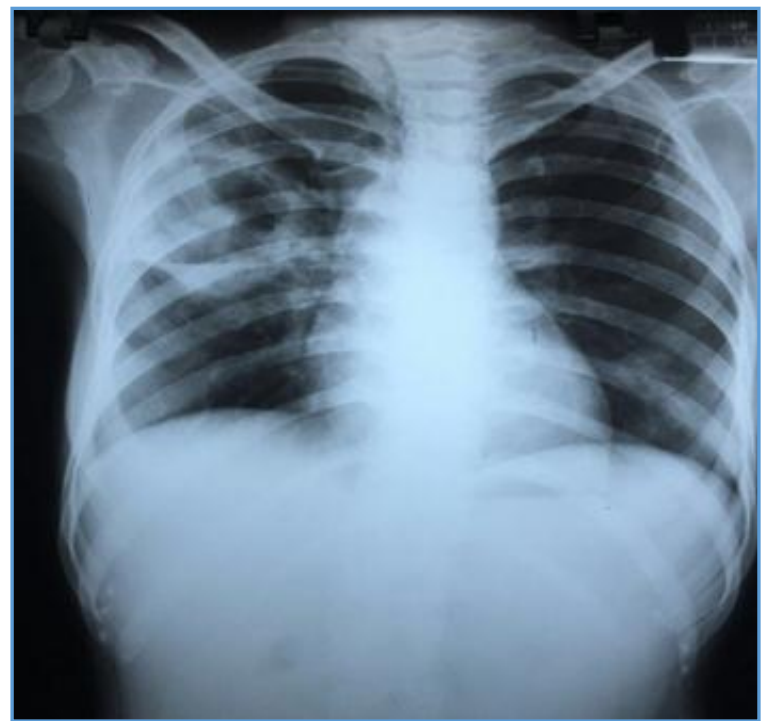

Figure 1. CXR PA View-RUZ, RMZ Thick Walled Cavity with Air Fluid Level

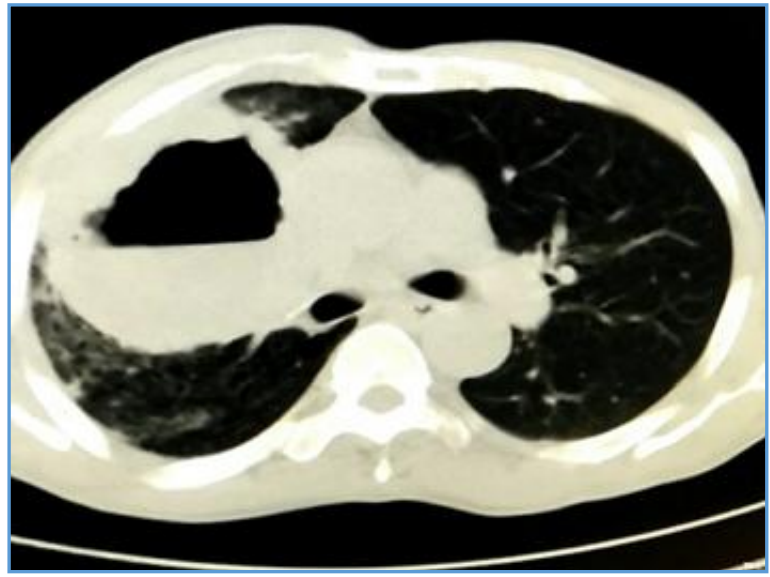

Figure 2. CT Chest RML Thick Walled Cavity with Air Fluid Level

\section{MANAGEMENT}

For further evaluation, fibreoptic bronchoscopy (Fig. 3) was done. Narrowed right middle bronchus was noted. BAL culture showed E. coli. No fungal elements/ growth noted. Bronchial washings was negative for malignant cytology and AFB smear. 
Patient was started on empirical IV broad-spectrum antibiotics initially and later according to sensitivity pattern. Patient did not show any significant improvement. During the course of hospital stay, patient developed right-sided chest pain and also developed abdominal pain in the right lumbar region for which ultrasonogram abdomen was done. USG revealed a heterogeneous mass lesion in both the adrenals that was noted on CT abdomen, which revealed findings highly suggestive of Adrenal Metastasis. CT guided biopsy (Fig. 2) was done from both the walls of the cavity in the lung and adrenal lesions. Histopathological examination done revealed moderately differentiated Adenocarcinoma.

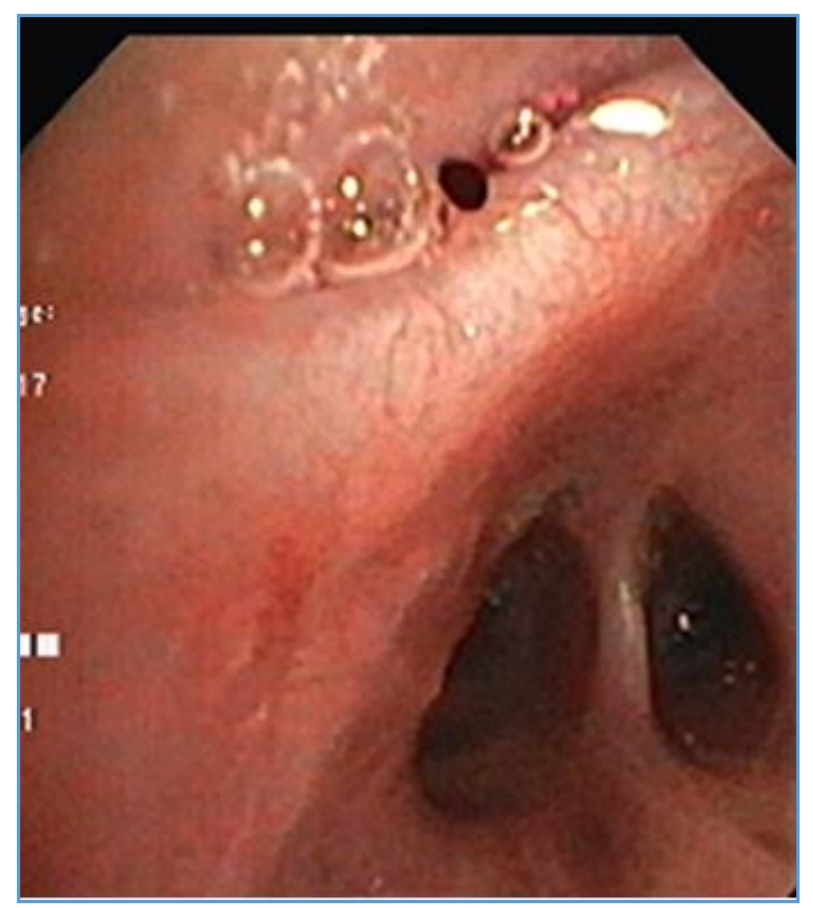

Figure 3. FOB revealing Narrowed Right Middle Lobe Bronchus

\section{PATHOLOGICAL DISCUSSION}

Section of lung biopsy specimen (Fig. 4 and 5) stained with haematoxylin and eosin examined with $40 \mathrm{X}$ magnification showed linear cores of fibrocollagenous tissue with an infiltrating neoplasm composed of cells arranged in nests, trabeculae, glands and cords. The cells were having scant-tomoderate cytoplasm, pleomorphic and hyperchromatic nuclei. Multinucleated tumour cells and a few mitotic figures were noted.

Section of Adrenal Biopsy specimen showed fragments of tissue exhibiting a neoplasm composed of cells arranged in dyscohesive pattern. The cells are small to varying sizes and many of them are large showing scant-to-moderate amount of cytoplasm and with highly pleomorphic hyperchromatic nuclei.

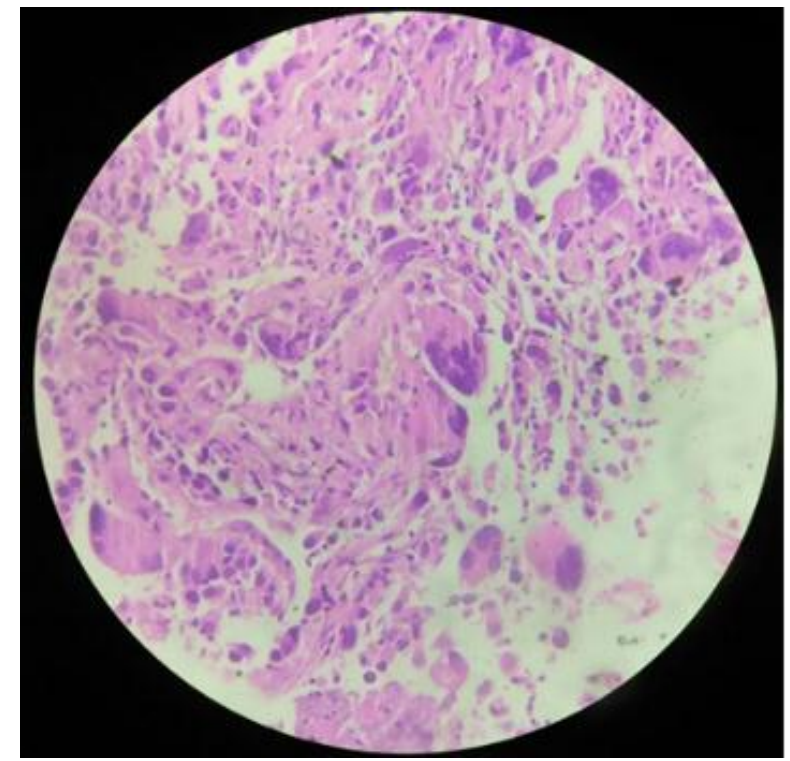

Figure 4.

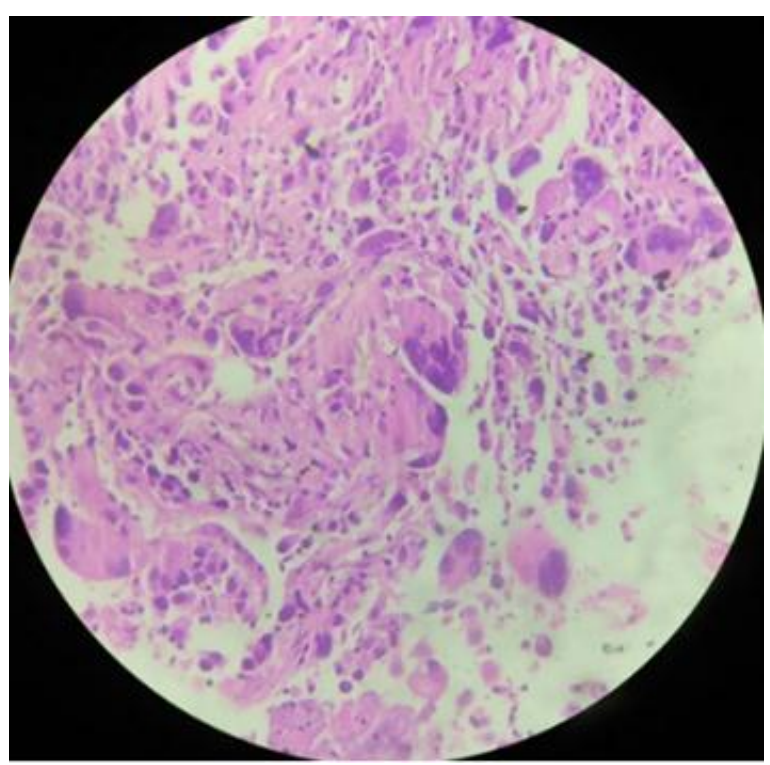

Figure 4 and 5. Histopathologic Slide Stained with Haematoxylin and Eosin Stain (40X Magnification) showing Tumour Giant Cells and Tumour Cluster Cells

\section{FINAL DIAGNOSIS}

The final diagnosis was stage IV Bronchogenic Carcinoma Moderately Differentiated Adenocarcinoma with Adrenal Metastasis.

\section{DISCUSSION}

The presentation of primary lung cancer as cavitation is not rare. Cavity on chest x-rays was reported in around 2\% - 16\% of primary lung carcinomas ${ }^{1-6}$ and with CT in $22 \%$ of primary lung carcinomas. ${ }^{7}$ The most common histological type of lung cancer to cavitate is squamous cell carcinoma $(82 \%$ of cavitary lung cancer) followed by adeno and large cell carcinoma.3,8 Multiple cavitary lesions in primary lung cancer are rare. Multifocal Bronchoalveolar Carcinoma can occasionally have multiple cavitary lesions. Small cell carcinoma never cavitates. In our case we had a thick walled cavity proven as Adenocarcinoma, which was an unusual finding. $9-11$ 
A primary lung cancer cavitates in three ways. The first mechanism is cavitary necrosis due to breakdown of growth itself. The second mechanism is stenotic abscess due to infection, inflammation and breakdown of lung parenchyma distal to the obstruction caused by the growth. The third mechanism is spill-over abscess. Although the mechanism is often difficult to ascertain, cavity in cancer most often results due to rapid tumour growth that exceeds the blood supply with resultant necrosis.

Radiological features of cavity that suggest malignancy include wall thickness, spiculations in margins and irregularity in inner and outer margins. Cavity wall thickness at its thickest section was the most useful predictor of malignancy. ${ }^{12,13}$ It is reported that $94 \%$ of cavities with a wall thickness of $\leq 4 \mathrm{~mm}$ were benign. Cavities with wall thickness of $5-15 \mathrm{~mm}$ were mixed. Similarly, $90 \%$ cavities with a wall thickness $>15 \mathrm{~mm}$ were usually malignant. Another study showed that $81 \%$ of cavitating malignancies were associated with overexpression of epidermal growth factor receptor (EGFR) and this high EGFR levels might be associated with rapid growth, necrosis and formation of cavity. ${ }^{7}$ The presence of cavity in primary lung malignancy is associated with a bad prognosis. ${ }^{14}$

Another study reported the differentiation of malignant and benign cavitary nodules using CT findings. ${ }^{15}$ In this study, $29 \%$ of benign cavitary nodules had a notch and in contrast $54 \%$ of malignant cavitary nodules had a notch. An irregular wall was found in $49 \%$ of malignant nodules and in $26 \%$ of benign nodules. It was also noted that a linear margin, bronchial wall thickening, satellite nodules, consolidation and ground-glass attenuation were significantly more frequent in benign lesions than in malignant ones. Although, these findings might be helpful in differentiating benign from malignant cavitary nodules to some degree, the CT findings of benign and malignant cavitary nodules may overlap.

Other unusual findings of primary cavitating lung malignancy include thin-wall cavitation and air-crescent sign. ${ }^{8}$ Although, "air-crescent sign" is often associated with an inflammatory process, lung cancer can also have an aircrescent sign rarely. Such cases may be benefited with PET scan. ${ }^{16,17}$ Contrarily, mycetoma also can arise from a cavitary lesion within lung cancer.18

Miura et al $^{19}$ studied the characteristics of cavitating adenocarcinoma of lung divided as 4 types pathologically- 1 . Central necrosis: central ischaemia was suspected; 2 . Cancer cell lining: the inner wall of the cavity was lined by viable cancer cells without necrosis. The cause of this type may be detachment of the central portion of a papillary growth tumour without necrosis; 3. Bronchial expansion: the inner wall was composed of cancer cells and bronchus. This mainly caused by ectatic change of peripheral bronchi following tumour invasion to more central bronchi; 4. Alveolar expansion: the inner wall was composed of cancer cells and alveoli. Detachment of destroyed alveoli or invasion along the wall of cavities of a honeycomb lung was suspected as a possible cause.

\section{CONCLUSION}

This case is reported to highlight the atypical presentation of Bronchogenic carcinoma masquerading as a lung abscess. The most common histological type to cavitate is a Squamous cell carcinoma, but here we report a case of cavitating
Adenocarcinoma which is another unusual finding. Knowledge of atypical presentation of Bronchogenic malignancy is crucial in early suspicion and diagnosis, which in turn has a direct relation to the disease outcome. Differentiating malignant cavitary lesion and benign cavitary lesions in patients may be challenging. Radiology may help in narrowing differential diagnosis. However, a comprehensive approach in assessment of the patient including symptoms and correlation of clinico-radiological data is often needed to obtain the accurate diagnosis.

\section{REFERENCES}

[1] Dodd GD, Boyle JJ. Excavating pulmonary metastases. Am J Roentgenol Radium Ther Nucl Med 1961;85:27793.

[2] Chiu FT. Cavitation in lung cancers. Aust N Z J Med 1975;5(6):523-30.

[3] Chaudhuri MR. Primary pulmonary cavitating carcinomas. Thorax 1973;28(3):354-66.

[4] Felson B, Wiot JF. Some less familiar roentgen manifestations of carcinoma of the lung. Semin Roentgenol 1977;12(3):187-206.

[5] Miller RR, McGregor DH. Haemorrhage from carcinoma of the lung. Cancer 1980;46(1):200-5.

[6] Mouroux J, Padovani B, Elkaïm D, et al. Should cavitated bronchopulmonary cancers be considered a separate entity? Ann Thorac Surg 1996;61(2):530-2.

[7] Onn A, Choe DH, Herbst RS, et al. Tumor cavitation in stage I non-small cell lung cancer: epidermal growth factor receptor expression and prediction of poor outcome. Radiology 2005;237(1):342-7.

[8] Vourtsi A, Gouliamos A, Moulopoulos L, et al. CT appearance of solitary and multiple cystic and cavitary lung lesions. Eur Radiol 2001;11(4):612-22.

[9] Weisbrod GL, Towers MJ, Chamberlain DW, et al. Thinwalled cystic lesions in bronchioalveolar carcinoma. Radiology 1992;185(2):401-5.

[10] Weisbrod GL, Chamberlain D, Herman SJ. Cystic change (pseudo cavitation) associated with bronchioloalveolar carcinoma: a report of four patients. J Thorac Imaging 1995;10(2):106-11.

[11] Görich J, Gamroth A, Beyer-Enke S, et al. Differential computed tomographic diagnosis of cavity-forming space-occupying lesions of the lung. Rofo 1987;147(5):479-85.

[12] Woodring JH, Fried AM, Chuang VP. Solitary cavities of the lung: diagnostic implications of cavity wall thickness. AJR Am J Roentgenol 1980;135(6):1269-71.

[13] Woodring JH, Fried AM. Significance of wall thickness in solitary cavities of the lung: a follow-up study. AJR Am J Roentgenol 1983;140(3):473-4.

[14] Kolodziejski LS, Dyczek S, Duda K, et al. Cavitated tumour as a clinical subentity in squamous-cell lung cancer patients. Neoplasma 2003;50(1):66-73.

[15] Honda 0, Tsubamoto $M$, Inoue $A$, et al. Pulmonary cavitary nodules on computed tomography: differentiation of malignancy and benignancy. J Comput Assist Tomogr 2007;31(6):943-9.

[16] Wang LF, Chu H, Chen YM, et al. Adenocarcinoma of the lung presenting as a mycetoma with an air crescent sign. Chest 2007;131(4):1239-42. 
[17] Shuji B, Jiro F, Yoko F, et al. Cavitary lung cancer with an aspergilloma-like shadow. Lung Cancer 1999;26(3):195-8.

[18] Torpoco JO, Yousuffuddin M, Pate JW. Aspergilloma within a malignant pulmonary cavity. Chest 1976;69(4):561-3.
[19] Miura H, Taira O, Hiraguri S, et al. Cavitating adenocarcinoma of the lung. Ann Thorac Cardiovasc Surg 1998;4(3):154-8. 